\title{
Progress towards a molecular-level understanding of Curcuma alismatifolia
}

\author{
Yuan-Yuan Li, Qi-Lin Tian, Hui-Wen Yu and Luan-Mei Lu \\ Provincial Key Laboratory of Landscape Plants with Fujian and Taiwan Characteristics/ \\ College of the Bioscience and Technology, Minnan Normal University, Zhangzhou, China
}

\begin{abstract}
Summary
Curcuma alismatifolia are widely used as an ornamental plant in Thailand, Cambodia and China, which have become increasingly popular as cut flowers, garden plants and urban landscaping flowers. Thus it is of great interest to understand the physiologic and molecular characteristics in the $C$. alismatifolia cultivars. Although only a very limited number of molecular biology experiments were conducted in $C$. alismatifolia, the obtained data currently have led to a better understanding of their genetic variation and the responses to environmental stimuli. This review presents the current available genetic markers, new breeding varieties, bioactive compounds (in different parts of the plant) and the stress physiology in $C$. alismatifolia cultivars, which may be beneficial for the future marker-assisted selective breeding and for the studies on the molecular mechanisms. Future challenges and research opportunities in the physiology and molecular biology are also discussed.
\end{abstract}

\section{Keywords}

Curcuma alismatifolia, bioactive compounds, essential oils, genetic variation, marker, stress physiology

\section{Introduction}

Curcuma alismatifolia is a member of the Zingiberaceae family that has been widely used as bulbous ornamental flowers. It is found throughout south and south-east Asia, with a few species extending to China, Australia and the South Pacific (Khumkratok et al., 2012). This species of perennial herbaceous entered the mainland market of China about twenty years ago, and has recently become popular for its colorful, distinctive and long-lasting inflorescences. Currently, approximately more than 20 species of $C$. alismatifolia are now introduced and cultivated in southern and southeastern regions of China. In general, light, temperature and fertilizer are all important factors for the growth of $C$. alismatifolia. Like a lot of typical tropical plants, C. alismatifolia prefer warm wet weather, growing in a range from $20^{\circ} \mathrm{C}$ to $32^{\circ} \mathrm{C}$. Thus, their natural blooming period could last from June to the end of October, exactly making up the shortage of summer cut flower market in mainland China (Lin and Lu, 2003).

C. alismatifolia are also known as "tropical tulip" for their similar flower patterns. The aboveground flowering stem of C. alismatifolia consists of a spike inflorescence with white/ pink-purplish coma bracts in the upper part and green coma bracts in the lower part (Figure 1). The colorful bracts which

\section{Significance of this study}

What is already known on this subject?

- Curcuma alismatifolia has increasingly become popular as an ornamental in tropics and subtropics. In the last few years, updated knowledge on the morphology and growth of $C$. alismatifolia, as well as physiology and metabolism of nitrogen and carbohydrate, have been provided. However, few of progress in molecular biology has been addressed.

What are the new findings?

- Available genetic markers and derived genetic variations were summarized. Bioactive compositions and their antioxidant characteristics were displayed and compared. We also addressed the effects of plant hormone on the stress physiology of $C$. alismatifolia cultivars.

What is the expected impact on horticulture?

- The overall impact of this review could be of interest for all researchers dealing with flower quality and genetic diversity and interested in molecular assisted breeding, natural antioxidants and stress physiology.

resembled the corolla of lotus, were their main ornamental parts (Hwang et al., 2014). Underground organs are composed of a stubbed bulb with several buds and roots for nutrition storage and absorption (Apavatjrut et al., 1999). For the regular growing period in mainland China, the bulbs spontaneously enter into dormancy for 20 to 60 days after planting in the spring (March to April). High temperature and enough water will promote earlier germination (Criley, 2013), and totally 4 to 6 generations could be reproduced during one growth cycle. The high reproductive rate possessed by C. alismatifolia is of great importance in actual production (Lin and Lu, 2003).

The review from Ruamrungsri (2015) in the last few years has provided updated knowledge on the morphology and growth of $C$. alismatifolia, as well as the physiology and metabolism of nitrogen and carbohydrate. Following the development of molecular biology technology, more research has been conducted on the genetic law and the molecular regulating mechanisms regarding the ornamental plant. The recent development of high-throughput sequencing has greatly simplified biochemical studies on C. alismatifolia, offering the possibility of genetics and breeding (Taheri et al., $2018,2019)$. Here, we outline the development of genetic diversity in C. alismatifolia supported by studies at cytogenetic and PCR-based levels. Advances in flower physiology 

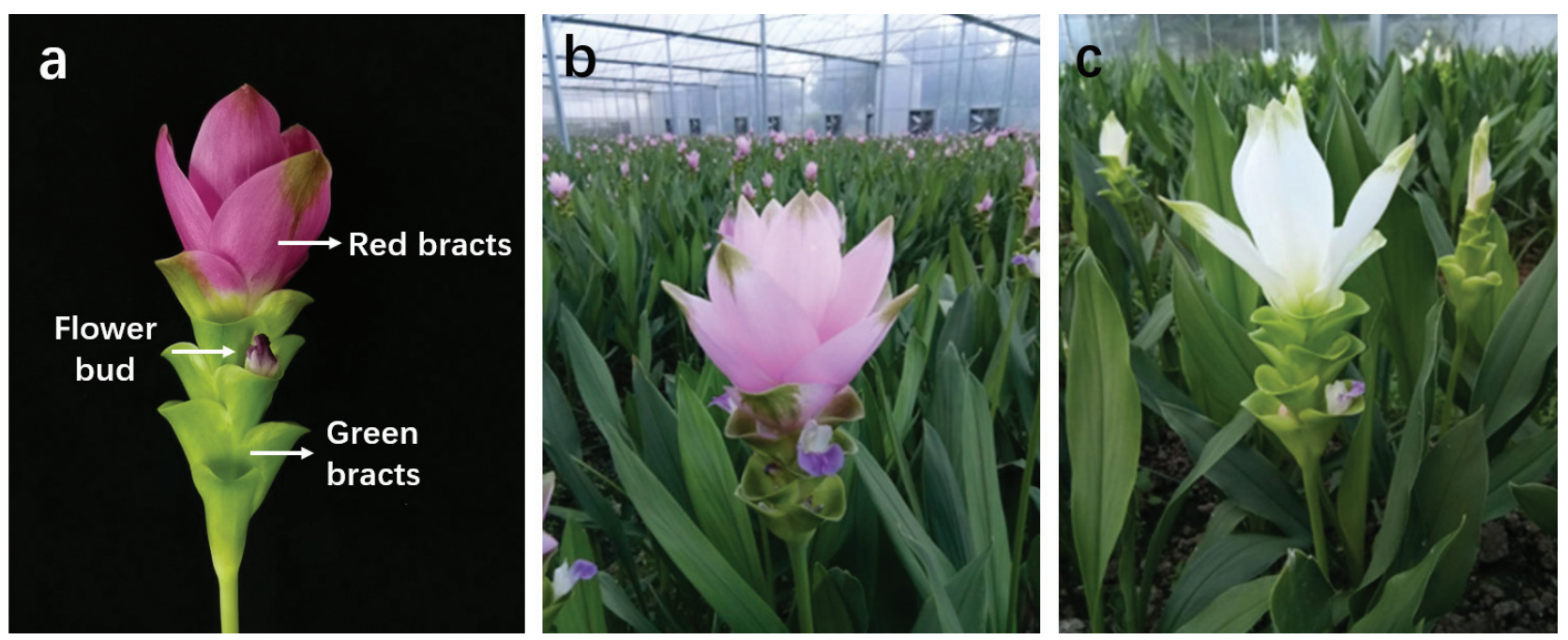

Figure 1. Morphology of a spike inflorescence in Curcuma alismatifolia 'Dutch Red' and C. alismatifolia cultivars. (a) Inflorescence of 'Dutch Red'; (b) 'Chiang Mai Pink'; (C) 'UB Snow 701'.

and gene cloning are introduced to discuss the feasibility of molecular breeding in $C$. alismatifolia. The shortcomings of molecular mechanism research and the potential directions of future development are explored to a broad back ground for flower color improvements in ornamental constus (Zingiberaceae) plant.

\section{Genetic diversity and marker design}

Genome size and chromosome numbers are important cytogenetic characters that significantly influence morphological traits. Moreover, polyploidy plays a significant role in evolution and genetic diversity patterns in members of Curcuma (Záveská et al., 2011). Karyological surveys has showed that the basic chromosome number in the majority of Curcuma corresponds to $7 \times$ cytotypes, however, it appears that the somatic chromosome number of $C$. alismatifolia counts $2 n=32$, which differs from the majority of Curcuma species whose basic chromosome numbers are multiples of 7, suggesting a cytogenetic cause related to morphological differences between them (Apavatjrut et al., 1996; LeongŠkorničková et al., 2007). Worth mentioning is that the exact length of genome size is still unclear in C. alismatifolia species due to lack of genome sequencing. A study on the chloroplast genome sequence of Curcuma flaviflora published recently will provide an effective method for reference in future C. alismatifolia genomic analysis (Zhang et al., 2016).

By definition, molecular markers are genetic loci that can be easily tracked and quantified in a population and may be associated with a particular gene or trait of interest (Hayward et al., 2015). Therefore, molecular marker techniques can be useful and serve as a powerful tool to assess the genetic variability in ornamental plants for identification of C. alismatifolia varieties in future breeding programs (Parthasarathy et al., 2006). Using of molecular markers, including inter-simple sequence repeats (ISSRs), random amplified polymorphic DNA (RAPD) and simple sequence repeats (SSRs), in characterizing C. alismatifolia has been performed on typical cultivars (Table 1) (Syamkumar and Sasikumar, 2007; Siju et al., 2010; Taheri et al., 2012, 2014). 39 RAPD and 8 ISSR markers were yielded polymorphic bands among 15 Curcuma species which were then placed into seven groups (Syamkumar and Sasikumar, 2007). The first identification of SSRs in turmeric was reported by Sigrist et al. (2009). Totally, 17 polymorphic SSRs were selected from 231 microsatellite repeats. Those were then used for genetic relationship analysis in five C. alismatifolia varieties, namely 'Chiang Mai Pink', 'Sweet Pink', 'Doi Tung 554', 'Chiang Mai Red', and 'Kimono Pink' (Taheri et al., 2014a). Genetic similarity of SSRs showed that the 'Kimono Pink' was distinguished from the other four varieties. Though, it was different from the outcome revealed by ISSRs (Taheri et al., 2012) since the 'Kimono Pink' showed high similarity with 'Chiang Mai Red'. Using the polymorphic SSR primers, Taheri et al. (2014b) again observed dozens of varied alleles among irradiated individual plants with different doses of radiation, that would be applicable in the next molecular marker assisted breeding in C. alismatifolia. Based on high-throughput sequencing, Mao et al. (2018) excavated totally 19,902 SSRs in C. alismatifolia var. 'Chiang Mai Red', out of which 50 pairs of microsatellite primers were designed for future genetic breeding research. Recently, 'Chiang Mai Pink' and 'UB Snow 701', two C. alismatifolia cultivars with the distinctive color appearances, were continually subjected to Illumina sequencing and de novo transcriptome assembly. Among the 8,955 designed EST-SSR primers, 17 EST-SSR markers presented divergency in genetic diversity among $C$. alismatifolia cultivars (Taheri et al., 2019), reflecting similar findings as reported earlier in the genetic studies of $C$. alismatifolia using SSR markers (Siju et al., 2010; Taheri et al., 2012). Though the cluster analysis are somewhat congruent with classification based on morphological descriptions proposed by earlier works (Hagiladi et al., 1996; Maciel and Criley, 2003), the need of molecular markers in combination with morpho-taxonomic and cytological studies while revising the genus, is currently more urgent. These advances will provide an important basis for exploring genetic diversity, genetic linkage and marker-assisted breeding in different varieties of $C$. alismatifolia, and they also will lay a theoretical foundation for molecular research of Curcuma species in the future.

\section{New varieties cultivation}

C. alismatifolia, which has wide variations in bract color, has been cultivated for ornamental use. Currently, there is intense interest in the new varieties with novel or improved traits for the plant. The development of biotechnology opened more ways for the breeding of $C$. alismatifolia species. Though genetic engineering could assist the genetic improvement of $C$. alismatifolia to create new varieties, ap- 
TABLE 1. Summary of primers developed for analyzing genetic diversity of Curcuma alismatifolia.

\begin{tabular}{|c|c|c|c|}
\hline Primer ID & Primer type & Primer pair $\left(5^{\prime}-3^{\prime}\right)$ & References \\
\hline Clon01 & SSR & $\begin{array}{l}\text { F: ACTGGACTGTCCGAGAGCAT } \\
\text { R: TCGTTTAGCGACAACGGATT }\end{array}$ & Sigrist et al. (2009) \\
\hline Clon04 & SSR & $\begin{array}{l}\text { F: TAAATTTGCGAAGGCAATCC } \\
\text { R: CCGCAGAGGAATTGAAGAG }\end{array}$ & \\
\hline Clon08 & SSR & $\begin{array}{l}\text { F: CCGGTGAGGGTGATATCTTG } \\
\text { R: AAGCTCAAGCTCAAGCCAAT }\end{array}$ & \\
\hline Clon09 & SSR & $\begin{array}{l}\text { F: GGAGGAGGCAGTTGATTTGT } \\
\text { R: GCTTTGGTGGCTAGAGATGC }\end{array}$ & \\
\hline Clon10 & SSR & $\begin{array}{l}\text { F: GTGGGAATTGGATTGCTCTC } \\
\text { R: GAGAACTCCCCATGCTTCAG }\end{array}$ & \\
\hline Clon11 & SSR & $\begin{array}{l}\text { F: GGGCTTTGTTTAGTTGTCGTG } \\
\text { R: CAGGAATGAAGTCGGCAAC }\end{array}$ & \\
\hline Clon12 & SSR & $\begin{array}{l}\text { F: GATTGGATCACATGGTGTGC } \\
\text { R: TGGGTTGATGGTTTCTCTGTT }\end{array}$ & \\
\hline Clon14 & SSR & $\begin{array}{l}\text { F: TCAGTCGAGGGGTTCCTACT } \\
\text { R: GAGAGCTGATCGCAAAAACC }\end{array}$ & \\
\hline UBC_811 & ISSR & GAGAGAGAGAGAGAGAC & Taheri et al. (2012) \\
\hline UBC_812 & ISSR & $(G A)_{8} A$ & \\
\hline UBC_818 & ISSR & CACACACACACACACAG & \\
\hline UBC_826 & ISSR & ACACACACACACACACC & \\
\hline UBC_834 & ISSR & $(\mathrm{AG})_{8} \mathrm{YT}$ & \\
\hline UBC_835 & ISSR & AGAGAGAGAGAGAGAGYC & \\
\hline UBC_841 & ISSR & GAGAGAGAGAGAGAGAY & \\
\hline UBC_842 & ISSR & GAGAGAGAGAGAGAGAYG & \\
\hline UBC_847 & ISSR & CACACACACACACACARC & \\
\hline UBC_848 & ISSR & CACACACACACACACARG & \\
\hline UBC_850 & ISSR & GTGTGTGTGTGTGTGTYC & \\
\hline UBC_880 & ISSR & GGAGAGGAGAGGAGA & \\
\hline 11 & ISSR & $(\mathrm{GA})_{9} \mathrm{C}$ & \\
\hline 12 & ISSR & $(\mathrm{GA})_{9} \mathrm{~T}$ & \\
\hline 13 & ISSR & $(\mathrm{GA})_{9} \mathrm{~A}$ & \\
\hline 17 & ISSR & $(\mathrm{CT})_{8} \mathrm{G}$ & \\
\hline CuAl04 & SSR & $\begin{array}{l}\text { F: GAGAGATCAGTCATCCCTATTCG } \\
\text { R: ACAACGTTATTATTGCCTGGAGA }\end{array}$ & Taheri et al. (2019) \\
\hline CuAl08 & SSR & $\begin{array}{l}\text { F: CAGACACTTATCGTCGTTGGTTA } \\
\text { R: AAACTGAAACATACTCCACCACC }\end{array}$ & \\
\hline CuAl10 & SSR & $\begin{array}{l}\text { F: TCTTCTGCTAGATACTTCAGCGG } \\
\text { R: TGTCTGGGGAAATCACTAACATC }\end{array}$ & \\
\hline CuAl11 & SSR & $\begin{array}{l}\text { F: CATTATCTGTTCACTGGTAGCCC } \\
\text { R: AAATTTGAACTGTTTCCTGATGC }\end{array}$ & \\
\hline CuAl12 & SSR & $\begin{array}{l}\text { F: CACATCGGAAATTTAAGCATCA } \\
\text { R: GGCTCCTGAACCACCACC }\end{array}$ & \\
\hline CuAl13 & SSR & $\begin{array}{l}\text { F: AAAGAAGGCCTCTTCATCATCTC } \\
\text { R: AAGCCATCTTTCTCCTTCTTCCT }\end{array}$ & \\
\hline CuAl14 & SSR & $\begin{array}{l}\text { F: CTTGACTCCATCTCTCCATTCAG } \\
\text { R: AGTGTTCCACTACGGGGACTAAT }\end{array}$ & \\
\hline CuAl15 & SSR & $\begin{array}{l}\text { F: CTTGACGAGATTCGAGGTGAC } \\
\text { R: GCTGGCTTACTACATGGATTCTG }\end{array}$ & \\
\hline CuAl16 & SSR & $\begin{array}{l}\text { F: TTGCTTCTTTCGTCTCTTGATTC } \\
\text { R: AACAGTGAGATCGATCCAGGTAA }\end{array}$ & \\
\hline CuAl17 & SSR & $\begin{array}{l}\text { F: GCTATTCTTCAGCAAAACAAAGG } \\
\text { R: TTGGAGCACAAAATAACAACTCA }\end{array}$ & \\
\hline CuAl18 & SSR & $\begin{array}{l}\text { F: CAGAAACGACAAGGCTCTGAC } \\
\text { R: GTAGAGCAGAGTTATGGAGTCGC }\end{array}$ & \\
\hline CuAl20 & SSR & $\begin{array}{l}\text { F: AAGACGTATGTCTCCGAGATGC } \\
\text { R: GTGAAACAGAGGAGAAGAACGAC }\end{array}$ & \\
\hline CuAl21 & SSR & $\begin{array}{l}\text { F: CAATTCATCCCTCGTCAGAGT } \\
\text { R: CGGCTAGGGAGTTGGGAT }\end{array}$ & \\
\hline CuAl22 & SSR & $\begin{array}{l}\text { F: GTGCTTCATCCTCTGGGACTT } \\
\text { R: CATCTTAGCTCTACCCAAATCCA }\end{array}$ & \\
\hline CuAl23 & SSR & $\begin{array}{l}\text { F: CTCCTCCACCTCACTAATTTCCT } \\
\text { R: AGGAGTACCTCATGAAGAGCCA }\end{array}$ & \\
\hline CuAl24 & SSR & $\begin{array}{l}\text { F: ACGTTCAAGATTTCCGAGGATAC } \\
\text { R: GATAAATCAACCCAAATGGACAA }\end{array}$ & \\
\hline CuAl25 & SSR & $\begin{array}{l}\text { F: GACTTCTGTGCTGACAAGTCAAA } \\
\text { R: CTTCTTTTCTCCGCAATTAGGAT }\end{array}$ & \\
\hline
\end{tabular}




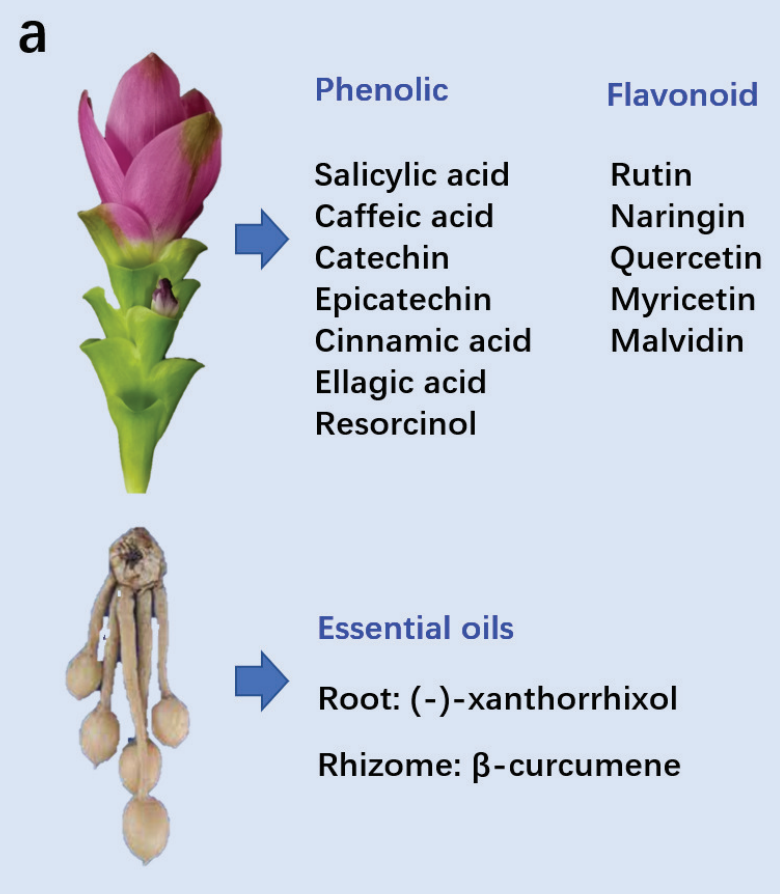

b

Free Radical Scavenging Activity

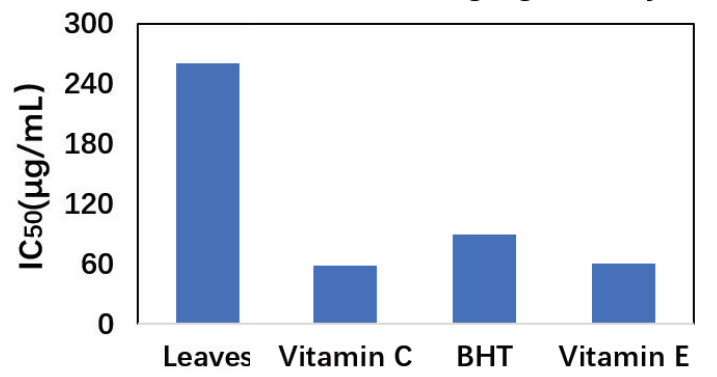

C

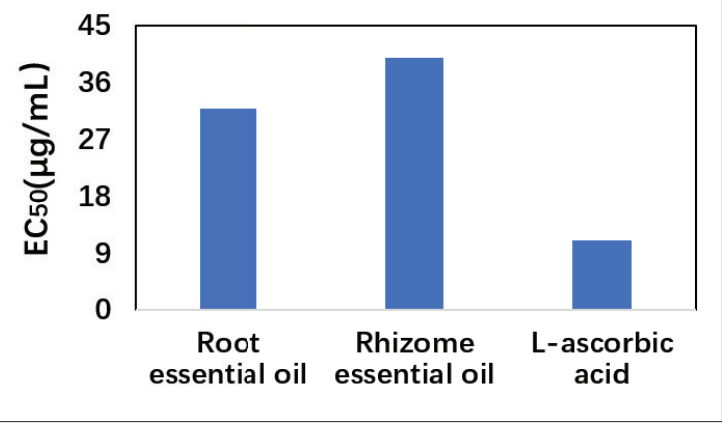

FIGURE 2. Compositions and the antioxidant activities of bioactive compounds in different parts of Curcuma alismatifolia. (a) Bioactive compounds in color bracts, roots and rhizomes. (b) The IC50 values of leaf extracts and standards in free radical scavenging activities (Taheri et al., 2014c); (c) The EC50 values of root essential oil, rhizome essential oil and standard (L-ascorbic acid) in free radical scavenging activities (Theanphong and Mingvanish, 2017). BHT: Butylated hydroxytoluene. IC50 means the inhibitor concentration at 50\% inhibitory effect. EC50 means the concentration at 50\% of maximum clinical efficacy (either inhibition or stimulation). The picture of root and rhizome in (a) was referenced from Ruamrungsri (2015).

plication of this established technique in C. alismatifolia is still very rare now. Since Topoonyanont et al. (2005) firstly reported success with micropropagation of $C$. alismatifolia from retarded shoots, several protocols for tissue culture, regeneration and genetic transformation have been established for C. alismatifolia using retarded buds as explant in most case (Zhao et al., 2005; Mao et al., 2006; Mahadtanapuk et al., 2006; Jiang et al., 2019). Moreover, the antisense 1-aminocyclopropane-1-carboxylic acid (ACC) synthase gene isolated from $C$. alismatifolia was introduced via agrobacterium-mediated transformation, in an attempt to prolong vase life of the inflorescence after harvesting (Mahadtanapuk et al., 2006). During the extension of $C$. alismatifolia in China, the application of tissue culture technique breaks the dormancy limits, thus playing an important role in the year-round supply of cut flowers of $C$. alismatifolia. For example, Zeng et al. (2014) discovered the mutant, namely Hongguanyin, with garnet bracts and higher flowering rate from pink C. alismatifolia species. Then large numbers of seedlings were obtained from the method of tissue culture and rapid propagation, effectively shortening the breeding time (Shang et al., 2010).

\section{Bioactive compounds}

C. alismatifolia is belonging to Zingiberaceae family which have been in use as a source of therapeutic compounds in traditional medicine (Kumar et al., 2011). Though C. alismatifolia is known for its high ornamental value, a variety of bioactive compounds, which possess typical antioxidant function, have been isolated from the different parts of the plant (Nakayama et al., 2000; Taheri et al., 2014c; Koshioka et al., 2014). In the leaves of $C$. alismatifolia var. 'Sweet Pink', the phenolic compounds are mainly composed of salicylic acid, caffeic acid, catechin, epicatechin, cinnamic acid, ellagic acid and resorcinol, while flavonoid compounds consist mainly of rutin, naringin, quercetin and myricetin (Figure 2a) (Taheri et al., 2014c). Phenolic and flavonoid compounds are known to slow or delay lipid oxidation, separate free radicals or single oxygen (Rice-Evans et al., 1996; Rice-Evans et al., 1997; Coskun et al., 2005). These natural antioxidants extracted from colorful bracts of $C$. alismatifolia sweet pink have better performance in free radical scavenging activity/antioxidant activity (Figure $2 \mathrm{~b}$ ), thus they have the potential to be the alternative sources of healthier products for consumers to prevent chronic conditions, such as cancer, atherosclerosis, and neurological diseases (Coskun et al., 2005; Marinova et al., 2005). Flavonoids consisting mainly of anthocyanins, flavonols and flavanols, are as well the pigment responsible for bract color in C. alismatifolia (Petrussa et al., 2013). Researchers analyzed the bracts of several Curcuma species in detail and found the existence of several kinds of anthocyanins. Totally, four major anthocyanins, delphinidin 3-O-rutinoside, cyanidin 3-O-rutinoside, petunidin 3-O-rutinoside and malvidin 3-O-rutinoside, were identified in the bracts of $C$. alismatifolia (Koshioka et al., 2014), while the malvidin 3-O-rutinoside is the most abundant (Nakayama et al., 2000; Koshioka et al., 2014).

Essential oils, one group of naturally-occurring substances from roots and rhizomes of $C$. alismatifolia, have also been found to have anti-oxidative properties. Recently, Theanphong and Mingvanish (2017) reported that the root and rhizome essential oils of $C$. alismatifolia obtained from hydrodistillation were rich in (-)-xanthorrhixol and $\beta$-curcumene. Their anti-oxidative capabilities showed significantly higher than L-ascorbic acid (Figure 2c), which were similar to other Curcuma species previously reported (Singh et al., 2010; Rahman et al., 2014; George and Britto, 2015; Tamta 
et al., 2016). Altogether, C. alismatifolia have the potentials to be the alternative sources of natural antioxidant, food supplements and pharmaceutical applications in the future.

\section{Stress physiology}

Being sessile organisms, plants are often exposed to a wide array of abiotic stresses, including drought, heat, cold and salinity. The response of plant to environmental changes has always been one of the hot fields in plant stress physiology. C. alismatifolia is originating from tropical and subtropical areas thus prefers warm $\left(20-32^{\circ} \mathrm{C}\right)$ and humid climate (Lin and Lu, 2003; Khumkratok et al., 2012). In recent years, C. alismatifolia has been introduced and cultivated in many parts of China, where the temperature is gradually decreased to less than $10^{\circ} \mathrm{C}$ from early December. Typically, the bulbs of C. alismatifolia cannot resist a temperature of less than $9^{\circ} \mathrm{C}$ while the temperature during their growth period cannot be lower than $15^{\circ} \mathrm{C}$ (Lin et al., 2013; Liu et al., 2017). Under low-temperature stress, cells would significantly increase the activity of peroxidase and accumulated more proline in the leaves of $C$. alismatifolia (Lin et al., 2013).

To adapt to adverse environmental conditions, phytohormones play critical roles and serve as ideal candidates for mediating defense responses (Verma et al., 2016; Boontiang et al., 2019). It has been shown that all chemical treatments (including abscisic acid (ABA), salicylic acid (SC), brassinolide (BR), 6-BA, paclobutrazol could enhance bulbs of cold tolerance in various C. alismatifolia species (Liu et al., 2017). ABA increases bulb cold resistance mainly through the adjustment of osmotic adjustment system, while 6-BA treatment mainly through the regulation of antioxidant enzyme system to achieve the purpose (Liu et al., 2017). Moreover, the paclobutrazol treatment can induce water stress tolerance. Jungklang and Saengnil (2012) have reported that paclobutrazol could increase the tolerance of $C$. alismatifolia Gagnep. 'Chiang Mai Pink' plants under limited water by reducing proline and malondialdehyde content. Jungklang et al. (2015) further supplemented that paclobutrazol induced the water stress tolerance of the plants by maintaining fresh weight and relative water content, reducing electrolyte leakage and proline, enhancing the levels of vitamin $\mathrm{C}$ and $\mathrm{E}$ antioxidants, and as well increasing the activities of the antioxidative enzymes in the leaves. It is not unique, the growth regulators gibberellin plus benzyladenine are also proven to have positive effects on the fresh weight keeping during the postharvest handling of $C$. alismatifolia cultivars (Favero et al., 2017). In addition, flowers of $C$. alismatifolia treated with 1-methylcyclopropene, a substance against ethylene emission, could retain higher contents of anthocyanin and the fresh weights, respectively (Chutichudet et al., 2011).

One problem of growing $C$. alismatifolia is bacterial wilt caused by Ralstonia solanacearum, which affects the quality of the rhizome exports (Lekawatana and Pituck, 1998). Recently, the researchers first isolated three strains of Ralstonia solanacearum from the 'Chiang Mai Pink' in Curcuma alismatifolia Gagnep. and conducted phylogenetic analyses (Thano and Akarapisan, 2018). These data are useful for the study of disease epidemiology in C. alismatifolia.

\section{Outlook and conclusions}

Over the last decade, considerable research on physiological and molecular performance in C. alismatifolia Gagnep. has been conducted, and we have learned a great deal about the genetic diversity using molecular markers, the variety breeding basing on mutation and tissue cultivation, the availability of bioactive compounds and their response to external stresses. Those basic knowledges derived from the reviewed papers will provide useful information on how to track the regulating mechanisms, flower pigmentation and environmental responses of this plant, and can be modified for use in other Curcuma species. The progress in high-sequencing bioinformatics and tissue culture technique for commercially important $C$. alismatifolia cultivars means that a full armory of molecular biology techniques can now be achieved, including the cloning of functional genes, molecular-assisted selective breeding and gene transformation.

Because the world market for cut flowers is in increasingly high demand year by year, varieties with new colors or long shelf lives, were urgently requested by wholesalers. The future of $C$. alismatifolia therefore looks promising, especially in the mainland market of China, as we embark on an era in which C. alismatifolia gets high reputation in both cut flower markets and urban landscapes. Cultivars of $C$. alismatifolia as well have appearance at important international conferences held in China. In the future, it may also be possible to use flowers as sources of natural anti-oxidants thus to expand their added value.

\section{Acknowledgments}

The authors would like to thank the Zhangzhou Natural Science Fund (ZZ2020J10), the Regional Development Project of Fujian Provincial Science and Technology Department (2020N3010) and the Fujian Provincial Education and Science Foundation (JAT190356) for financial support.

\section{Conflict of interest}

The authors declare that this study was conducted in the absence of any commercial relationships that could lead to any potential conflict of interest.

\section{Author contribution statement}

LYY and LLM wrote the manuscript. LYY and LLM each contributed to the design and review of the final manuscript. TQL and YHW contributed to the revision of the paper.

\section{References}

Apavatjrut, P., Sirisawad, T., Sirirugsa, P., Voraurai, P., and Suwanthada, C. (1996). Studies on chromosome number of seventeen Thai Curcuma species. Proc. $2^{\text {nd }}$ Nat. Conf. on Flower and Ornam. Plants 2, 86-99.

Apavatjrut, P., Anuntalabhochai, S., Sirirugsa, P., and Alisi, C. (1999). Molecular markers in the identification of some early flowering Curcuma L. (Zingiberaceae) species. Ann. Bot. 84, 529-534. https:// doi.org/10.1006/anbo.1999.0936.

Boontiang, K., Chutichudet, B., and Chutichudet, P. (2019). Effect of paclobutrazol on growth and development of Curcuma alismatifolia Gagnep. grown off-season. Naresuan Univ. J.: Sci. and Technol. 1,1-8.

Chutichudet, P., Chutichudet, B., and Boontiang, K. (2011). Effect of 1-MCP on vase life and other postharvest qualities of patumma (Curcuma alismatifolia) cv. Chiang Mai Pink. Trends Hortic. Res. 1, 1-11. https://doi.org/10.3923/thr.2011.1.11.

Coskun, O., Kanter, K., Korkmaz, A., and Oter, S. (2005). Quercetin, A flavonoid antioxidant, prevents and protects streptozotocininduced oxidative stress and $\beta$-cell damage in rat pancreas. Pharmacol. Res. 51, 117-123. https://doi.org/10.1016/j. phrs.2004.06.002.

Criley, R.A. (2013). Blueprint programming for year-round forcing of Curcuma alismatifolia. Acta Hortic. 1000, 209-216. https://doi. org/10.17660/ActaHortic.2013.1000.27. 
Favero, B.T., Lima, G.P.P., and Dole, J. (2017). Curcuma alismatifolia vase life. Ornam. Hortic. 23, 101-106. https://doi.org/10.14295/ oh.v23i1.989.

George, M., and Britto, S.J. (2015). Phytochemical and antioxidant studies on the essential oil of the rhizome of Curcuma aeruginosa Roxb. Int. Res. J. Pharm. 6, 573-579. https://doi.org/10.7897/22308407.068113

Hagiladi, A., Yang, X.H., Umiel, N., and Gilad, Z. (1997). Curcuma alismatifolia. I. Plant morphology and the effect of tuberous root number on flowering date and yield of inflorescences. Acta Hortic. 430, 747-754. https://doi.org/10.17660/ActaHortic.1997.430.119.

Hayward, A.C., Tollenaere, R., Dalton-Morgan, J., and Batley, J. (2015). Molecular marker applications in plants. Meth. Mol. Biol. 1245, 1327. https://doi.org/10.1007/978-1-4939-1966-6_2.

Hwang, S.A., Lee, P.O., Choi, M.P., and Kim, Y.A. (2014). Inflorescence development of Curcuma alismatifolia 'Chiangmai Pink'. Kor. J. Hortic. Sci. Technol. 32, 623-627. https://doi.org/10.7235/ hort.2014.14088

Jiang, B.Y., Zhu, M.Q., Ruan, Y.Z., Shen, L.L., Chen, Y.M., Ma, W.Q., Huang, L.Y., Liang, J.L., and Liang, Y.T. (2019). A method of tissue culture and rapid propagation of Curcuma alismatifolia. Patent CN109169292A.

Jungklang, J., and Saengnil, K. (2012). Effect of paclobutrazol on patumma cv. Chiang Mai Pink under water stress. Songklanakarin J. Sci. Technol. 34, 361-366.

Jungklang, J., Saengnil, K., and Uthaibutra, J. (2015). Effects of waterdeficit stress and paclobutrazol on growth, relative water content, electrolyte leakage, proline content and some antioxidant changes in Curcuma alismatifolia Gagnep. cv. Chiang Mai Pink. Saudi J. Biol. Sci. 24, 1505-1512. https://doi.org/10.1016/j.sjbs.2015.09.017.

Khumkratok, S., Boongtiang, K., Chutichudet, P., and Pramaul, P. (2012). Geographic distributions and ecology of ornamental Curcuma (Zingiberaceae) in Northeastern Thailand. Pak. J. Biol. Sci. 15, 929-935. https://doi.org/10.3923/pjbs.2012.929.935.

Koshioka, M., Umegaki, N., Boontiang, K., Pornchuti, W., Thammasiri, K., Yamaguchi, S., Tatsuzawa, F., Nakayama, M., Tateishi, A., and Kubota, S. (2015). Anthocyanins in the bracts of Curcuma species and relationship of the species based on anthocyanin composition. Nat. Prod. Commun. 10, 453-456. https://doi. org/10.1177/1934578X1501000320.

Kumar, G., Karthik, L., and Rao, K.V.B. (2011). A review on pharmacological and phytochemical properties of Zingiber officinale Roscoe (Zingiberaceae). J. Pharm. Res. 4, 2963-2966.

Lekawatana, S., and Pituck, O. (1998). New floricultural crops in Thailand. Acta Hortic. 454, 59-64. https://doi.org/10.17660/ ActaHortic.1998.454.5.

Leong-Škorničková, J., Šída, O., Jarolímová, V., Sabu, M., Fér, T., Trávníček, P., and Suda, J. (2007). Chromosome numbers and genome size variation in Indian Species of Curcuma (Zingiberaceae). Ann. Bot. 100, 505-526. https://doi.org/10.1093/aob/mcm144.

Lin, J.S., and Lu, L.M. (2003). Preliminary study on growth habits and cultivation techniques of Curcuma alismatifolia. Fujian Sci. Technol. Trop. Crops 28, 13-15.

Lin, J.S., Lu, L.M., and Zhao, Q.Q. (2013). Preliminary study on cold resistance of Curcuma alismatifolia. Fujian Sci. Technol. Trop. Crops $38,1-5$.

Liu, J.X., Xu, X.H., and Ding, H.Q. (2017). Study on cold resistance of Curcuma hybrid 'Laddawan' bulbs. Mol. Plant Breed. 15, 2796-2803.

Maciel, N., and Criley, R.A. (2003). Morphology, growth and flowering behavior of Curcuma zedoaria. Acta Hortic. 624, 111-116. https:// doi.org/10.17660/ActaHortic.2003.624.14.

Mahadtanapuk, S., Topoonyanont, N., Handa, T., Sanguansermsri, M., and Anuntalabhochai, S. (2006). Genetic transformation of Curcuma alismatifolia Gagnep. using retarded shoots. Plant Biotechnol. 23, 233-237. https://doi.org/10.5511/plantbiotechnology.23.233.

Mao, L.H., Liu, J.X., Ding, H.Q., Xu, X.H., and Tian, D.Q. (2018). Microsatellite characterization analysis and primers design of the whole transcriptome of Curcuma alismatifolia. Mol. Plant Breed. 16, 7407-7414.

Mao, X.X., Li, W.J., Wang, J.H., Tang, L.N., and Zhang, L.M. (2006). Tissue culture and rapid propagation of Curcuma alismatifolia. Northern Hortic. 5, 23.

Marinova, D., Ribarova, F., and Atanassova, M. (2005). Total phenolics and total flavonoids in Bulgarian fruits and vegetables. J. Univ. Chem. Technol. Metall. 40, 255-260.

Nakayama, M., Roh, M.S., Uchida, K., Yamaguchi, Y., Takano, K., and Koshioka, M. (2000). Malvidin 3-rutinoside as the pigment responsible for bract color in Curcuma alismatifolia. Biosci. Biotechnol. Biochem. 64, 1093-1095. https://doi.org/10.1271/ bbb.64.1093.

Parthasarathy, V.A., and Sasikumar, B. (2006). Biotechnology of Curcuma. CAB Reviews: Persp. Agric., Vet. Sci., Nutr. Nat. Res. 1(020), 9. https://doi.org/10.1079/PAVSNNR20061020.

Petrussa, E., Braidot, E., Zancani, M., Peresson, C., Bertolini, A., Patui, S., and Vianello, A. (2013). Plant flavonoids - Biosynthesis, transport and involvement in stress responses. Int. J. Molec. Sci. 14, 14950 14973. https://doi.org/10.3390/ijms140714950.

Rahman, A., Afroz, M., Islam, R., Islam, K.D., Hossain, M.A., and Na, M. (2014). In vitro antioxidant potential of the essential oil and leaf extracts of Curcuma zedoaria Rosc. J. Appl. Pharm. Sci. 4, 107-111.

Rice-Evans, C.A., and Miller, N.J. (1996). Structure-antioxidant activity relationships of flavonoids and phenolic acids. Free Rad. Biol. Med. 20, 933-956. https://doi.org/10.1016/0891-5849(95)02227-9.

Rice-Evans, C.A., Miller, N.J., and Paganga, G. (1997). Antioxidant properties of phenolic compounds. Trends Plant Sci. 2, 152-159. https://doi.org/10.1016/S1360-1385(97)01018-2.

Ruamrungsri, S. (2015). The physiology of Curcuma alismatifolia Gagnep. as a basis for the improvement of ornamental production. Eur. J. Hortic. Sci. 80, 316-321. https://doi.org/10.17660/ eJHS.2015/80.6.7.

Shang, H.L., Chen, X., Chen, Z.L., and Zeng, S.J. (2010). Tissue culture and rapid propagation of a new Curcuma alismatifolia variety 'Hongguanyin'. Northern Hortic. 18, 154-156.

Sigrist, M.S., Pinheiro, J.B., Azevedo-Filho, J.A., and Colombo, C.A. (2009). Development and characterization of microsatellite markers for turmeric (Curcuma longa). Plant Breed. 129, 570-573. https:// doi.org/10.1111/j.1439-0523.2009.01720.x.

Singh, G., Kapoor, I.P.S., Singh, P., De Heluani, C.S., De Lampasona, M.P., and Catalan, C.A. (2010). Comparative study of chemical composition and antioxidant activity of fresh and dry rhizomes of turmeric (Curcuma longa Linn.). Food Chem. Toxicol. 48, 1026-1031. https://doi.org/10.1016/j.fct.2010.01.015.

Syamkumar, S., and Sasikumar, B. (2007). Molecular marker based genetic diversity analysis of Curcuma species from India. Sci. Hortic. 112, 235-241. https://doi.org/10.1016/j.scienta.2006.12.021.

Taheri, S., Abdullah, T.L., Abdullah, N.A.P., and Ahmad, Z. (2012). Genetic relationships among five varieties of Curcuma alismatifolia (Zingiberaceae) based on ISSR markers. Genet. Mol. Res. 11, 30693076. https://doi.org/10.4238/2012.August.31.4.

Taheri, S., Abdullah, T.L., Abdullah, N.A.P., Ahmad, Z., Karimi, E., and Shabanimofrad, M.R. (2014a). Assessing the genetic relationships of Curcuma alismatifolia varieties using simple sequence repeat markers. Genet. Mol. Res. 13, 7339-7346. https://doi. org/10.4238/2014.September.5.12. 
Taheri, S., Abdullah, T.L., Ahmad, Z., and Abdullah, N.A. (2014b). Effect of acute gamma irradiation on Curcuma alismatifolia varieties and detection of DNA polymorphism through SSR marker. Biomed Res. Int. 2014, 631813. https://doi.org/10.1155/2014/631813.

Taheri, S., Abdullah, T.L., Noor, Y.M., Padil, H.M., Sahebi, M., and Azizi, P. (2018). Data of the first de novo transcriptome assembly of the inflorescence of Curcuma alismatifolia. Data in Brief 19, 2452-2454. https://doi.org/10.1016/j.dib.2018.07.038.

Taheri, S., Abdullah, T.L., Rafri, M.Y., Harikrishna, J.A., Werbrouck, S.P.O., Teo, C.H., Sahebi, M., and Azizi, P. (2019). De novo assembly of transcriptomes, mining, and development of novel EST-SSR markers in Curcuma alismatifolia (Zingiberaceae family) through Illumina sequencing. Sci. Rep. 9, 3047. https://doi.org/10.1038/s41598-01939944-2.

Tamta, A., Prakash, O., Punetha, H., and Pant, A.K. (2016). Chemical composition and in vitro antioxidant potential of essential oil and rhizome extracts of Curcuma amada Roxb. Cogent Chem. 2,1168067. https://doi.org/10.1080/23312009.2016.1168067.

Thano, P., and Akarapisan, A. (2018). Phylotype and sequevar of Ralstonia solanacearum which causes bacterial wilt in Curcuma alismatifolia Gagnep. Lett. Appl. Microbiol. 66, 384-393. https://doi. org/10.1111/lam.12857.

Theanphong, O., and Mingvanish, W. (2017). Chemical constituents and antioxidant activities of essential oils from roots and rhizomes of Curcuma alismatifolia Gagnep. from Thailand. J. Appl. Sci. 16, 105111. https://doi.org/10.14416/j.appsci.2017.10.S16.

Topoonyanont, N., Chongsang, S., Chujan, S., Somsueb, S., and Nuamjareen, P. (2005). Micropropagation scheme of Curcuma alismatifolia Gagnep. Acta Hortic. 673, 705-712. https://doi. org/10.17660/ActaHortic.2005.673.98.

Verma, V., Ravindran, P., and Kumar, P.P. (2016). Plant hormonemediated regulation of stress responses. BMC Plant Biol. 16, 86. https://doi.org/10.1186/s12870-016-0771-y.

Záveská, E., Fér, T., Šída, O., Leong-Škorničková, J., Sabu, M., and Marhold, K. (2011). Genetic diversity patterns in Curcuma reflect differences in genome size. Bot. J. Linn. Soc. 165, 388-401. https:// doi.org/10.1111/j.1095-8339.2011.01122.x.

Zeng, X.H., Zeng, S.J., Liu, W., Deng, M.H., and Lin, W.H. (2014). Breeding and cultivation techniques of a new variety Curcuma alismatifolia cv. Hongguanyin. Agric. Sci. in Guangdong Prov. 12, 51-54.

Zhang, Y., Deng, J.B., Li, Y.Y., Gao, G., Ding, C.B., Zhang, L., Zhou, Y.H., and Yang, R.W. (2016). The complete chloroplast genome sequence of Curcuma flaviflora (Curcuma). Mitochondrial DNA, Part A. 27, 3644-3645. https://doi.org/10.3109/19401736.2015.1079836.

Zhao, Y.J. (2005). Study on tissue culture and rapid propagation of Curcuma alismatifolia. Anhui Agric. Sci. 2, 255-255.

Received: Oct. 5, 2019

Accepted: Dec. 10, 2019

Address of authors:

Yuan-Yuan Li, Qi-Lin Tian, Hui-Wen Yu and Luan-Mei Lu* Provincial Key Laboratory of Landscape Plants with Fujian and Taiwan Characteristics / College of the Bioscience and Technology, Minnan Normal University, Zhangzhou 363000, China

*Corresponding author; E-mail: 358070295@qq.com 